\title{
The impact of COVID-19 on the global economy in the context of globalization
}

\author{
Shahla Huseynova ${ }^{1}$, Elmira Godjayeva ${ }^{2, *}$, and Vafa Huseynova ${ }^{1}$ \\ ${ }^{1}$ Azerbaijan State University of Economics, The Department of Economics, Istiglaliyyat 6, AZ1001 \\ Baku, Azerbaijan \\ ${ }^{2}$ Azerbaijan Tourism and Management University, The Department of Marketing, K.Rahimov str. \\ 822/23, AZ1072 Baku, Azerbaijan
}

\begin{abstract}
.
Research background: When analyzing the results, hypotheses were tested for the presence of a statistically significant relationship between the studied variables with a 5\% error risk. The chi-square method was used to test for a statistically significant relationship, and the Cramer coefficient was used to determine the strength of the relationship. A survey conducted in Azerbaijan found mostly moderate statistically significant relationships between individual variables.

Purpose of the article: The article discusses the most important aspects of the contemporary global problem of coronavirus infection COVID-19, shows the distribution of coronavirus across countries, analyzes the ability of different countries to counteract epidemics and pandemics by the Global Health Safety Index, shows the real situation of the effectiveness of the health systems of some countries in the fight against a pandemic. The aim of this study is to examine several aspects in connection with the pandemic and its impact on the education and tourism sector. The work also shows the impact of the pandemic on the global economy in general and on international tourism in particular. To activate the tourism market, the development of virtual tourism is proposed, which has great prospects in terms of quarantines and border closures.

Methods: The article applies such general scientific research methods as analysis and synthesis, a systematic approach, methods of comparisons, expert assessments, as well as a method of analyzing hierarchies.

Findings \& Value added: Universities - many of which rely heavily on revenue from their foreign intakes - are being pushed to the brink. Around the world, international students and their parents are weighing their options as the pandemic wreaks havoc like never before on the overseas university education business. What was relevant this morning is already outdated by noon. Our task is to track existing trends, moods and suggest some prospects for getting out of the situation or adapting to it.
\end{abstract}

\footnotetext{
*Corresponding author: e.qocayeva@atmu.edu.az
} 
Keywords: pandemic, international education, tourism, environment, strategic assessment.

JEL Classification: $F 01 ; F 60 ; 125 ; O 11 ; Z 32$

\section{Introduction}

On the basis of a sociological survey conducted by the authors in the context of new behavioral stereotypes (increased anxiety, concern about the guarantee of non-infection with COVID-19, etc.), to analyse the short-term and medium-term effects of the impact of the pandemic on domestic and inbound tourism in Azerbaijan.

In these works, attention is paid to the study of tourism infrastructure, the social and economic significance of the tourism industry is investigated.

In the course of the study, both general theoretical methods were used: analysis and synthesis, deduction and induction, generalization, theoretical modeling, methods of grouping and comparison, and empirical methods: document analysis, content analysis, sociological surveys (questionnaires and interviews).

The problems of the tourism sector are reflected in the works of Azerbaijani scientists and specialists Novruzova A., Nasirova O., Azizova R., Aliyeva M., Huseynova Sh.A. [1], E.M. Godjayeva [2], A.N.Eminov [3], Mammadova N.G. [4], F.P. Rahmanov [5], E.B.Suleymanov [6] and others.

The attitudes and stereotypes of behaviour of the population in the context of attitudes towards travel in the context of a pandemic, planning of tourist trips in Azerbaijan and outside the republic have not been sufficiently studied.

There is very little empirical data reflecting, on the one hand, the needs and interests of the population in the field of tourism in the near future (in the context of the temporary lifting of travel restrictions and partial resumption of air traffic), and, on the other hand, the real possibilities and limitations of the development of the tourism industry in the post-pandemic period.

\section{Methods}

Thus, in the presence of extensive scientific material on the problems of tourism in general, we do not have works devoted to assessing the short-term and medium-term effects of the spread of COVID-19 on domestic and inbound tourism, analysing the consequences of the imposed restrictions on the movement of citizens and the work of the industry, the effectiveness of measures to support the tourism industry. and the hospitality industry in a pandemic, the rational choice of tactics for the behaviour of the population, the peculiarities of reactions to compliance with sanitary regulations on the part of citizens, etc.

The Republic of Azerbaijan over a 27-year period after the restoration of independence in 1991 has made impressive progress in strengthening its statehood and socio-economic development.

Modern Azerbaijan is turning into an increasingly important factor in world and regional politics. This is primarily due to internal political stability, a stable economy, and a properly oriented and skilfully pursued foreign policy. As a result of the implementation of transnational transport, communication and energy projects, Azerbaijan has become the economic leader of the region and an important player on the global map of the world.

Since independence, the republic has successfully implemented important programs for the industrial and innovative development of the country, State programs for the socioeconomic development of the regions of the republic, carried out a land reform, implemented programs for the development of health care and education, reforming the system of social 
protection of the population, housing and road construction, etc. ., which ultimately had a positive effect on the growth rate of the well-being of the population of Azerbaijan.

Currently, it is being implemented adopted in 2016. "Strategic roadmap for the development of the national economy and its individual sectors" in order to accelerate industrial and innovative development, accelerated economic diversification and technological development of the country [7].

An increase in the level of income of the population, improvement of social and economic living conditions as a result of ongoing large-scale reforms, information accessibility, competition between travel companies, a wide range of destinations for tourism in the republic itself and abroad, interest in the culture and traditions of foreign countries - all this is significant. expanded opportunities for various layers of the population of Azerbaijan to make tourist trips within the republic, influenced the growth of the outbound tourism market.

\section{Results and Discussions}

In the first half of April 2020, a survey was conducted by Google Forms and disseminated online to examine citizens' attitudes towards travel in the face of the growing pandemic around the world. The survey was distributed in several languages - Bulgarian, Russian, English, Spanish. Most responses were received from Bulgaria and Azerbaijan - from 656 Bulgarian citizens and 417 Azerbaijani citizens, which are the subject of research in this article. Demographic analysis shows that $68 \%$ of respondents in both groups are women. However, if we consider the activity of different age subgroups, there are differences. The most widely represented age subgroup of respondents in the Bulgarian survey is 35-44 years old (37\%), and in the Azerbaijani survey - 18-24 years old (49.6\%). The same subgroup (1824 years old) answered the least to the citizens of Bulgaria - $11 \%$, and the citizens of Azerbaijan with the least number of answers - in the group over 55 years old $-7.9 \%$. These results should be taken into account in the conclusions of the study. Answers from Azerbaijan are dominated by the answers of the youngest people, while the answers from Bulgaria belong to the subgroup with the most active citizens in the labour process.

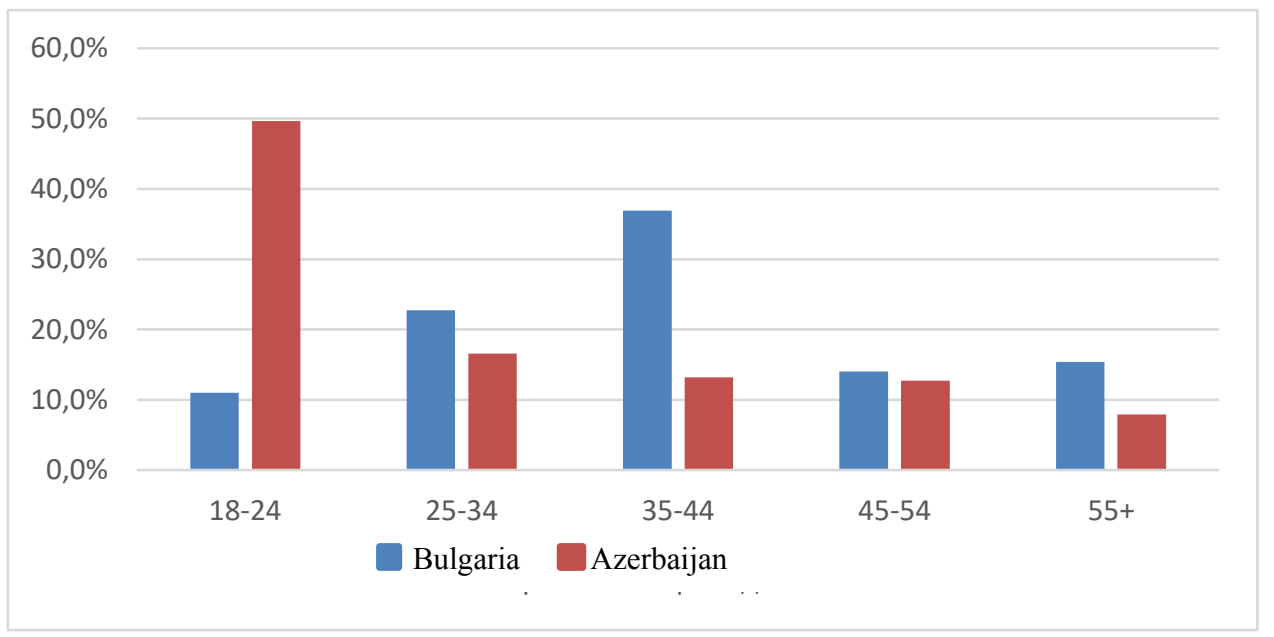

Fig. 1. Demographic age

In both groups, respondents with higher education prevail. This is $79.6 \%$ of the Bulgarian participants. $87.5 \%$ of the surveyed Azerbaijanis indicated higher education, and $42.2 \%$ schoolchildren or students, which indicates that a significant part of the participants are young 
people with good education. $36 \%$ of Bulgarian participants work in private companies, and $13.9 \%$ in Azerbaijan. 18.6\% of the Bulgarian respondents work in state-owned companies, and $24.7 \%$ in Azerbaijan. $13 \%$ of participants from Bulgaria have their own business, $3.6 \%$ are Azerbaijanis. The pensioners who took part in the survey make up $6.9 \%$ from Bulgaria and $1.7 \%$ from Azerbaijan.

$57.8 \%$ of respondents from Azerbaijan are single, and Bulgarians - half - $30.6 \%$. Bulgarian married couples with children make up $42.7 \%$ of the participants, while Azerbaijanis make up 34.3\%. Childless families from Bulgaria make up 17.2\%, from Azerbaijan - 4.8\%. Divorced and widowed Bulgarians make up 7.2\% and 2.3\%, respectively, and Azerbaijani respondents $-1.7 \%$ and $1.4 \%$, respectively.

In the ranking of countries' ability to resist epidemics and pandemics, the United States is in first place with a total score of 83.5. They have the highest score in the Early detection and reporting category for the rest of the world -98.2 points. The health care system's readiness to treat patients and protect its workers is higher in the United States than in other countries (Table 1). Despite the high marks of US medicine during the pandemic, the country was in complete collapse. The situation is not the best in other developed countries.

Table 1. The ability of different countries to respond to epidemics and pandemics by the Global Health Security Index, 2019

\begin{tabular}{|l|c|c|}
\hline \multirow{2}{*}{ Country } & \multirow{2}{*}{$\begin{array}{c}\text { Place in } \\
\text { rating }\end{array}$} & General \\
\cline { 3 - 3 } & & 83.5 \\
\hline USA & 1 & 77.9 \\
\hline Britannia & 2 & 75.5 \\
\hline Australia & 4 & 75.3 \\
\hline Canada & 5 & 72.1 \\
\hline Sweden & 6 & 70.2 \\
\hline South Korea & 9 & 68.2 \\
\hline France & 11 & 66.0 \\
\hline Germany & 14 & 65.9 \\
\hline Spain & 15 & 61.0 \\
\hline Belgium & 19 & 59.8 \\
\hline Japan & 21 & 59.7 \\
\hline Brazil & 22 & 56.2 \\
\hline Italy & 31 & 52.4 \\
\hline Turkey & 40 & 52.0 \\
\hline Georgia & 42 & 48.2 \\
\hline China & 51 & 44.3 \\
\hline Russia & 63 & 37.7 \\
\hline Iran & 97 & 34.2 \\
\hline Azerbaijan & 117 & \\
\hline
\end{tabular}

Source: $[8,9]$

The pandemic has become the most acute global problem today and its solution requires joint efforts of all countries of the world and various international organizations. As such, on April 24, 2020, heads of state and global health leaders made an unprecedented commitment to work together to accelerate the creation and production of new vaccines, tests and medicines for COVID-19 and ensure equitable access to them worldwide. Therefore, along with adherence to current anti-epidemic measures, such as social distancing and the identification and testing of all contacts of cases, there is an urgent need to develop innovative vaccines, diagnostics and treatments to combat COVID-19 ... Health leaders called on the world community and political leaders to support this unprecedented cooperation, and donors 
to provide the necessary resources to accelerate the achievement of its to accelerate work to protect humanity from the threat of COVID-19 [10].

\section{For both sides: analysis and comparison of perceptions of whether a pandemic exists.}

Tourism is among the industries hardest hit by the economic impact of the pandemic. The tourism and recreation sector is often influenced by external shocks - events taking place in specific host countries: military conflicts and terrorist threats, climate change and natural disasters, currency fluctuations, financial and economic crises, etc. These events can lead to a redistribution of travel to other regions.

However, such grandiose phenomena as the coronavirus pandemic can paralyze the global tourism market for an indefinite time (1). According to estimates by the United Nations World Tourism Organization (UNWTO), in 2020 the number of international tourists in the world may decrease by $20-30 \%$ compared to the growth projected at the beginning of January of this year of $3-4 \%$. This, in turn, can lead to losses of the tourism industry in the amount of $\$ 30-50$ billion [11].

In order to counter the spread of the pandemic, the vast majority of countries have closed their air traffic and restricted the entry of foreigners. According to the estimates of the International Air Transport Association (IATA), the total global loss of revenue from passenger air transportation in 2020 will amount to 50\% (\$ 434 billion) [12].

The World Tourism and Travel Council (WTTC) publishes forecasts of the economic impact of COVID-19 and various scenarios for the recovery of the tourism industry for different regions. In 2019, the tourism and travel industry employed 330 million workers. The contribution of this sector to GDP is $10.3 \%$ ( $\$ 8.9$ trillion), the share in world exports of services is about $28 \%$.

Overall, global estimates of job losses in tourism and travel range from 98.2 million to 197.5 million; the decline in the contribution of tourism and travel to global GDP is estimated by experts in the range from 2.686 trillion to 5.543 trillion dollars [13].

The spread of COVID-19 in Azerbaijan began on February 28, 2020, when the first case of COVID-19 coronavirus infection in the country created by the operational headquarters of the Cabinet of Ministers of Azerbaijan was registered. A citizen of Russia who crossed the border of Azerbaijan from Iran was infected.

Since March 19, 2020, an official website about COVID-19 has been operating in the country, informing about the current state of affairs in the fight against the virus in Azerbaijan, statistics on infections, as well as recommendations for the population and a chat with the operator for additional information.

It should be noted that the state borders of Azerbaijan and many countries were closed, universities and schools were also closed, entrance exams were cancelled or postponed, and enrolment plans were thwarted [14].

How will the crisis change the education sector in the long term?

For example, the administration of universities in the United States is increasingly afraid that their doors may not open during the fall semester. British universities are taking pounds of millions of pounds in losses as international students cancel or postpone their studies. Australia's leading colleges expect to spend US \$ 2.85 billion in service fees.

Major university entrance exams have been cancelled, including the International Baccalaureate, Cambridge Assessment International Education, and the SAT standardized final exam, which will affect students in more than 150 countries.

It is noted that, within the framework of the study abroad program, Azerbaijani students are currently studying at the leading universities in the USA, Germany, Great Britain, France, Italy, Spain, Sweden, the Netherlands, Norway and the Russian Federation at government expense. The competition for financing education abroad, in accordance with the relevant decree of President Ilham Aliyev, was held by the Youth Fund in 2019. 
One of the most important components of a successful fight against a global scourge was the immediate response of the Azerbaijani leadership to the threat of the spread of the virus.

What should be our concerns at this stage of the crisis that could have a direct impact on young people? (1) Learning loss (2) Dropout rates (3) Television education, virtual education, distance education, and what can be done in this area. In addition, it should be borne in mind that most countries have very unequal education systems, and these negative effects will be disproportionately felt across countries.

In addition to financial, humanitarian and medical donations to other countries and organizations, Azerbaijan has also demonstrated its solidarity with the states fighting the coronavirus pandemic.

In March - April 2020, scientists from universities in Bulgaria and Azerbaijan conducted a sociological study of the impact of the coronavirus pandemic on the tourism industry.

The total sample size for Azerbaijan was 417 respondents from different regions of Azerbaijan. The bulk of the respondents $-51.4 \%$ aged 24 to 55 years and more. $24.7 \%$ of respondents are civil servants (workers in the field of education, medicine, lawyers, economists, programmers, engineers), $42.2 \%$ are undergraduates, doctoral students and students of 2-4 courses of economic, tourism and legal specialties, $18.9 \%$ - work in the private sector (managers and employees in a private company, freelancers), $8.9 \%$ - retirees, housewives and the unemployed.

\section{Q1. Do you think there is a COVID-19 epidemic in your country?}

- No, the epidemic is already over

- Yes, the peak of the epidemic is still ahead

- Yes, now is the peak of the epidemic

- Yes, but I can't estimate whether the peak is coming or passed

To the question "Do you think there is a COVID-19 epidemic in your country?" The majority of respondents $(60.7 \%)$ answered in the affirmative.

$27.6 \%$ of survey participants are sure that there is no epidemic.

The percentage of respondents who believe the pandemic is in full swing was $7.2 \%$. Another $4.2 \%$ of those surveyed believe that the peak of the pandemic is still ahead.

It is noteworthy that even those who answered affirmatively to the question of the existence of a coronavirus pandemic in the country have no idea whether the peak of the pandemic is to be expected, or whether it has already passed.

This indicates that in the information space of the republic at the beginning of the pandemic there was too little news in the media on this topic. The scientific community, organizers of medicine, experts, specialists in the field of epidemiology and virology through the media were supposed to urgently inform the population about the threats that this virus brings to the world.

In a sense, a mitigating circumstance may be the fact that in March 2020, i.e. at the time of the survey, much was still not clear even to specialists, not that to the population. The republic had just entered quarantine, a detailed action plan was approved to mitigate the impact of the pandemic on socio-economic life, the number of infected and mortality were at a low level.

2. For both countries: analysis and comparison of relations for travel within the country or abroad.

Do you consider taking a tourist trip within your country at the earliest opportunity after the lifting of the state of emergency in your country?

Answer: Of 417 respondents, $23.3 \%$ answered yes, while $23.0 \%$ - no, more likely yes than no $-23.7 \%$, more likely no than yes $-30.0 \%$

The attitude to travel within the country after the abolition of quarantine.

The corona crisis has exacerbated trends in recent years: a decline in organized tourism and commitment to tour packages, an increase in eco-tourism, increased use of digital 
technologies, the use of online aggregators and platforms, individualization and personalization of offers, etc.

In general, in the near future, a decrease in the total number of both international and domestic tourist trips can be predicted.

This is facilitated by a number of factors: the global recession and the decline in the purchasing power of the population; widespread fears of COVID-19 infection among potential tourists; restriction of the range of tourist services associated with the need to distance themselves; rise in the cost of services for tourists; as well as the fear of infection, forcing potential tourists to avoid large crowds, a significant change in behavioral stereotypes (transition to more intensive online consumption, including virtual travel).

In addition, much more attention should be paid to the sanitary and epidemiological protection of resort areas than before.

At the same time, factors restraining the development of tourism, associated with antiepidemiological restrictions, will affect the market, at least before the start of mass vaccination.

In these conditions, the preservation and even the increase in domestic and inbound tourism despite the reduction in demand is possible only by replacing part of the outbound tourist flow with trips to Azerbaijan and promoting Azerbaijani tourist destinations in the global market. Tourist market participants should focus on domestic tourism, as it can recover faster than outbound tourism.

This will require changes in the structure of tourism supply, the introduction of new products and services to the market, flexible regulation and effective government support for the industry.

Thus, the pandemic has created favorable conditions for the development of domestic tourism in Azerbaijan. It is quite logical to expect an increase in the number of Azerbaijani tourists who would prefer to spend their summer holidays in 2020 inside the country. Such a vacation is easier to organize, it does not require visas and is associated with less risks, since it does not depend on the opening of borders between countries and, against the background of a decrease in the income of a certain part of the population, it will most likely be more affordable for residents of the republic in financial terms.

The survey materials showed that despite the difficult epidemiological and economic situation, residents of the republic plan to go on vacation this coming summer. Most tourists don't expect borders to open soon.

To the question: "Do you think about taking a tourist trip within your country at the earliest opportunity after the cancellation of the state of emergency in your country?" the opinions of the respondents were divided approximately equally.

Most do not want to sacrifice their vacation, but they make plans with caution. Traveling abroad in the near future remains questionable, therefore, when people were asked about holidays in the country, $47 \%$ said they were ready for it.

Among those surveyed, $53 \%$ are not ready to travel to Azerbaijan after self-isolation, despite the fact that they are already "tired" of quarantine. Moreover, $23 \%$ of residents of the republic are ready to categorically exclude long trips due to fear of contracting coronavirus.

The main reason for refusing to travel abroad in the summer of 2020 is the uncertainty that it will be possible "technically" - that the borders will be opened, hotels and other tourist service organizations will start working. Other reasons are a decrease in income, and fears for their health.

To the question: Given the COVID-19 pandemic and its impact on travel companies, are you planning to use a tour operator or travel agency when booking a hotel, purchasing an air ticket or a transfer?

More than half of the respondents $(52.8 \%)$ answered negatively to this question. What stops more than half of our fellow citizens? 
In our opinion, this testifies, first of all, to the fact that most likely, the respondents assume that the organizers of the tourist service of the republic, who have spent a lot of money during the quarantine, will "increase" prices for their services, which, superimposed on the drop in income of potential tourists, and leads to the refusal of the latter from the services of various intermediaries.

Of those who intend to use the services of travel intermediaries, slightly less than a third $(30.7 \%)$ indicated that they use the services of a tour operator or travel agency when booking a hotel. A slightly smaller proportion of respondents $(27.3 \% \%$ will use the services of intermediaries when buying an air ticket. About $12.5 \%$ are going to use the services of travel intermediaries to book a transfer.

To the question: If you decide to spend your vacation in a accommodation facility (hotel, living rooms, apartment or something else), would you use your own disinfectant to further clean the room and bathrooms?

The survey has shown that residents of the republic follow the recommendations of specialists on the use of antiseptic protective equipment in the premises.

Almost $9 / 10$ of the respondents $(90.6 \%)$ are going to use special disinfectants to protect against coronavirus infection while on vacation in residential premises.

The respondents also indicated that they use medicinal and natural remedies for antiviral protection. For the purpose of prevention, they often wash their hands and observe hygiene in an enhanced or normal mode. They also lead a healthy lifestyle, playing sports in quarantine conditions [6]. The vast majority use face masks and wear gloves and goggles as a means of protection against coronavirus. Some of the respondents, in response to a question posed by phone, stated that there were no remedies in pharmacies, as well as that their prices were too high. They gave examples of other countries where remedies are issued free of charge.

Only $9.4 \%$ of the respondents lead a normal life, rarely using additional disinfectants in their living quarters. A small part of the respondents neglect protective equipment, $2.9 \%$ in this group do not use any protective equipment.

When asked how the spread of the coronavirus affected the material possibilities of tourist travel, the majority of those surveyed (58.8\%) answered that they had enough funds to do this. And, nevertheless, a significant part (namely $41.2 \%$ ) of the population felt a deterioration in their financial situation since the announcement of the coronavirus pandemic. Due to this, they believe that their resources may not be sufficient for making tourist trips.

Of course, many reasons influenced the decrease in income: a decrease in orders and customers, a decrease in wages and employers' refusal to pay bonuses, loss of a part-time job, a reduction in the number of working days and leaving on forced unpaid leave, etc.

Tourism - both international and domestic - was among the industries most affected by the spread of the new coronavirus infection. At the same time, the factors constraining its development, associated both with sanitary procedures and with crisis behavioural and economic effects, will affect the industry for at least 3-5 years.

During this period, depending on the effectiveness of support measures for the travel industry and the hospitality industry, either its large-scale curtailment will occur, or its preservation and development due to import substitution and state support. The latter will require the cultivation and support of both the premium tourist segment and infrastructure for regional and local economy-format travel [15].

Promising areas of activity can be: expanding the functionality of existing tourist routes (for example, growing "services on the water" in the framework of cultural and educational travel); revival of historical sites and tourism in the footsteps of local cultural values; formation of new large cultural and tourist routes; development of industrial and agritourism, cruises, creation of a format for the work of tourist national parks. Interestingly, before the outbreak, the gold (oil) market was more inefficient during downward (upward) trends. 
During the COVID-19 outbreak period, we see that the results have changed. More precisely, we find that gold (oil) is more inefficient during upward (downward) trends. More importantly, both markets become more inefficient during the pandemic outbreak compared to the pre-COVID-19 period, showing us the negative impact of the pandemic on market efficiency for commodities [20]. The pandemic has been seriously affecting public health and national and global economies since the beginning of 2020. By 3 November 2020, the world's cumulative reported infections exceeded 46 million and the number of deaths reached 1.2 million (WHO 2020). The rapid spread of COVID-19 and its induced pandemic control through territory lockdown, travel bans and many other restrictions imposed on people's movements have seriously affected the economy of all countries across the world [16].

Nevertheless, what it is still widely firm about industrial policy implementation is conceiving it as a technical tool to achieve given goals, which are set from the outside of such debate. In other words, for both policy-makers and scholars the salient question is to assess the technical capacity, scale and effectiveness of all types of industrial policies to meet desired objectives. The discussion on these desired societal objectives underlying the design of industrial policy is often overlooked, generally pointing to productivity and competitiveness that in turn would allow for economic growth, higher incomes and socioeconomic progress [17]. The pandemic of COVID19 has necessitated the need for attention to the underserved and marginalised populations holistically, to prevent long-lasting adverse health outcomes. Economic stressors on the whole population will need mitigation and quick changes in policy would help. Finally, National Health Programs for communicable and NCDs must be re-vitalised and strengthened [18]. As the COVID-19 pandemic unfolds, governments around the world have been grappling with their dual responsibility to save lives and safeguard livelihoods. This has comprised a public health response and an economic response. Governments continue to attempt to find the tipping point between them; the deployment of public health measures that save lives from COVID-19 in the short-term, and safeguarding livelihoods in the medium term, which has the potential to save lives from subsequent economic crises [19]. The development of domestic and inbound tourism in the current conditions requires the extension of the crisis package of measures addressed to the affected industries (reduction of the tax burden, postponements, credit holidays), at least until 2022, state support for small tourism projects (for small and medium-sized businesses, impact - investments and social design), subsidizing regional tourism development programs from the budget.

\section{Conclusions}

The results of the study made it possible to analyze, on the one hand, the needs for specialists of different professions in the tourist business and qualification requirements for them, and, on the other hand, the current situation and the level of training of specialists in pilot institutes in tourism specialties. It was revealed that the level and directions of training of specialists does not fully meet the modern requirements of the tourism industry. At present, the standards that govern educational institutions, the names of the main professions used in various structures of the tourism business at all its levels, the list of required responsibilities and knowledge for a number of positions do not correspond to the current level of development of the tourism business [20].

In this regard, the results of the conducted marketing research of the tourism professions market can contribute to the improvement of standards and qualification requirements corresponding to the real needs of the tourism business, and also make it easier to compare with Western professions not only by name, but also at a qualitative level. 


\section{References}

1. Huseynova Sh.A, Mamadova A., Novruzova A., Nasirova O., Azizova R., Aliyeva M.(2019). Features of education financing in developing countries. Revista ESPACIOS, 40(26).

2. Godjayeva, E.M., Babayeva, S.J., Sadigova, U.F. (2020). Priority areas of socioeconomic development of the non-oil sector in Azerbaijan. In A. Ismayilov, K. Aliyev \& M. Benazic (Eds.). 55th International Scientific Conference on Economic and Social Development Development (pp. 438-442). Varazdin: Croatia.

3. Eminov, A., Suleymanov, E., Mirzayev, A., Aliyeva, I. (2019). The Dependence of Personnel Potential on Social Investment. The Case of the Tourism Sector. Expert Journal of Economics, 6(2), 56-60.

4. Mammadova N.G. (2020). Planning study abroad in a pandemic, materials of the conference "Priority areas of international economic relations in the XXI century". ATMU.

5. Suleymanov, E., Rahmanov, F.P., Özdemir, Y. (2018). Improving the Institutional Environment of the Innovation Economy in Azerbaijan. Online Academic Journal of Information Technology, 9(35), 7-15.

6. Rahmanov, F., Letunovska, N., Lyulyov, O. (2020). Marketing of social tourism. In A. Ismayilov, K. Aliyev \& M. Benazic (Eds.). 55th International Scientific Conference on Economic and Social Development Development (pp. 147-160). Varazdin: Croatia.

7. Levashenko A.D., Anes S.M. (2020). Measures to support the tourism sector in the COVID-19 crisis. Retrieved from: https://www.ranepa.ru/documents/monitoring /2020_10-112_April.pdf.

8. Covid-19 coronavirus pandemic. (2020, April 27). Retrieved from: https://www.worldometers.info/coronavirus/

9. Global Health Security Index. (2020). Retrieved from: https://www.ghsindex.org

10. Morozov, M.A. (2007). Economy and entrepreneurship in social and cultural services and tourism. M: Academy.

11. Shpyrnya, O.V. (2018). Trends in the development of the international market for tourist services. Scientific Bulletin of YIM, 1, 62-66.

12. Shcherbina, V.V. (2014). Social technologies: the history of the emergence of the term, transformation of content, current state. Sociological research, 7, 113-124.

13. Birzhakov, M.B. (2014). Introduction to tourism. SPb.: Gerda.

14. Recovery Scenarios 2020 \& Economic Impact from COVID-19Infographics. (2020). Retrieved from: https://wttc.org/Research/Economic-Impact/Recovery-Scenarios-2020Economic-Impact-from-COVID-19

15. Kortunov, V.V., Chudinov, V.A., Sokolova, E.Y. (2014). Tourism as a Way of Expanding Human Existence. World Applied Sciences Journal, 30(1), 124-127.

16. Impact of COVID-19 outbreak on asymmetric multifractality of gold and oil prices. (2020). Retrieved from: https://www.sciencedirect.com/science/ article/pii/S0301420720308618?via\%3Dihub

17. Impacts of COVID-19 on agriculture and rural poverty in China. (2020). Retrieved from: https://www.sciencedirect.com/science/article/pii/S2095311920634694

18. Industrial policy for sustainable human development in the post-Covid19 era. (2020). Retrieved from: https://www.sciencedirect.com/science/article/pii/ S0305750X20303429 
19. COVID-19 pandemic and challenges for socio-economic issues, healthcare and National Health Programs in India. (2020). Retrieved from: https://www.sciencedirect.com/science/article/pii/S1871402120301600

20. Public health and economic responses to COVID-19: finding the tipping point. (2020). Retrieved from: https://www.sciencedirect.com/science/article/pii/S0033350620301876

21. Dellaert, B., Arentze, T., Horeni, O. (2014). Tourists' Mental Representations of Complex Travel Decision Problems. Journal of Travel Research, 53, 3-11.

22. Hilman, H., Kaliappen, N. (2014). Market Orientation Practices and Effects on Organizational Performance. Empirical Insight from Malaysian Hotel Industry, 4(4), Art. No. 2158244014553590.

23. Rahmanov, F., Kostyuchenko, N., Smolennikov, D. (2020). Education for sustainable development as a tool to reach high quality in teaching. In A. Ismayilov, K. Aliyev \& M. Benazic (Eds.). 55th International Scientific Conference on Economic and Social Development Development (pp. 260-268). Varazdin: Croatia.

24. Huseynova, Sh.A. (2016). Reforming the higher education system of the Republic of Azerbaijan. Theoretical and Practical Aspects of Economics and Intellectual Property Mariupol, 14. 